$\xi=-1$

\title{
Fabrication and Mechanical Characterization of Stir Cast AA6063-Borosilicate-Fly Ash Hybrid Metal Matrix Composites
}

\author{
G. Jims John Wessley $^{1^{*}}$, A. Gaith Franklin ${ }^{2}$, S.J. Vijay ${ }^{3}$ \\ ${ }^{I}$ Department of Aerospace Engineering, Karunya Institute of Technology and Sciences, Coimbatore, Tamilnadu, India. \\ ${ }^{2}$ Department of Aerospace Engineering, Karunya Institute of Technology and Sciences, Coimbatore, Tamilnadu, India. \\ ${ }^{3}$ Department of Mechanical Engineering, Karunya Institute of Technology and Sciences, Coimbatore, Tamilnadu, India. \\ *Corresponding author E-mail: jims_john@ karunya.edu
}

\begin{abstract}
This paper presents the development and characterization of aluminium alloy 6063 based metal matrix composite with varying combinations of fly ash and Borosilicate reinforcements. In the present work, the aluminium alloy 6063 (AA) is taken at a constant 84 vol\% while the reinforcements Fly Ash (FA) and Borosilicate (B) are varied in the proportions of 2\%, 4\% 8\%, 125 and $14 \%$. Six samples were fabricated by stir casting and the mechanical properties were analyzed using tensile test, hardness test and wear test while the microstructure is analyzed by obtaining SEM and EDX images of the specimen. It is seen that both the reinforcements used in this study, increased the tensile and wear resistance of the alloy. The desirable mechanical and micro structural properties were found to be in the specimen with $84 \%$ AA, $14 \%$ FA and $2 \%$ B. The tensile strength of the aluminum alloy at this desirable combination is found to increase by $11.97 \%$, ductility by $36.75 \%$ and the wear resistance by $62 \%$. This metal matrix composite of AA6063 with fly ash and Borosilicate reinforcements can be used in automobile, aerospace and structural applications where wear resistance and tensile properties are mainly required.
\end{abstract}

\section{Introduction}

The Aluminum alloys of the series $6 \mathrm{XXX}$ have proven to have remarkable mechanical properties as well as better weldability which have led to the successful application of these alloys in numerous applications. On the other hand, Metal Matrix Composites formed using Aluminium and two or more constituents have received considerable attention due to its improved strength and other mechanical properties over conventional materials. These composites find large application in automotive and aerospace sectors due to the fact that their properties can be tailored in-line with the requirement by adding selected reinforcements.

Similarly the presence of Fly ash in Aluminium alloys at limited proportion increases the wettability, strength and hardness of the composite. Fly ash is one of the most inexpensive by-product that is available in plenty form the combustion of coal in power plants. It is also seen that the reinforcement of ceramic materials in the metal matrix composites results in composites that posses good physical and mechanical properties that is not possible to obtain using other alloys. Stir casting is one of the simple, flexible and cost-effective manufacturing methods for metal matrix composites. These Aluminium based metal matrix composites have successfully replaced conventional materials like Cast iron and Bronze in applications like drive shaft for light load vehicles, Car brake disk, stringers for aircraft fuselages, robotics, sporting goods, industrial process equipment, electronics packaging and medical instrumentation. The road ahead for the aluminum based metal matrix composite is very verdant as the aerospace and automobile sectors look for light weight composite materials.

\section{Literature Background}

Many researchers have performed researches on developing a variety of aluminium based metal matrix composites that are reported in the open literature. A brief summary of the recent works in the relevant area of this present study is reported here. Deepak Singla et.al (2013) evaluated the Mechanical properties of Al 7075-Fly ash composite material stir casted using varying proportions of Fly ash, Magnesium and Aluminium alloy 7075. The results of the weight of Fly ash was varied from $40 \mathrm{~g}$ to $10 \mathrm{~g}$ and the weight of Magnesium was varied between $10 \mathrm{~g}$ and $40 \mathrm{~g}$ and the result shows that the impact, tensile and hardness of the composite increased while the density decreased ${ }^{[1]}$. Sachin Malhotra et.al (2013) fabricated an Aluminium based hybrid composite using Aluminum 6061 Alloy, Fly ash \& Zirconia using Stir casting method. The weight percentage of Zirconia is varied from 5\% to $10 \%$ while the weight percentage of Fly ash is kept constant at $10 \%$. The result shows that hardness and ultimate tensile strength by 6 to $15 \%$ and 11 to $20 \%$ respectively ${ }^{[2]}$. Vamsi Krishna M et.al (2014) investigated the mechanical properties of hybrid metal matrix composite stir casted using Graphite, Silicon carbide and Aluminium alloy 6061. The amount of reinforcement is varied from $5-15 \%$ in steps of $5 \%$ by weight. The result shows that the maximum tensile strength was $192.45 \mathrm{Mpa}$ at $15 \mathrm{wt} \%$ and the density decreases with increase in $\mathrm{SiC} / \mathrm{Gr}$ while it increases with increase in $\mathrm{SiC}^{[3]}$. Jamaluddin Hindi et.al (2015) investigated the mechanical characterization of stir cast Al 6063 Matrix with $\mathrm{SiC}$ reinforced metal matrix composite. The result shows that the hardness and tensile strength increases with increase in $\mathrm{SiC}$ while the impact strength increases at first instance and later decreases ${ }^{[4]}$. Rajesh. P.V et.al (2016) fabricated an aluminium based hybrid composite with fly ash, Magnesium and Aluminium alloy 6063 
with varying combinations. The material was fabricated by stir casting method and it was found that the composite material with 90\% Aluminium, 5\% Silicon carbide and 5\% Magnesium is, 5 and 5 has the desirable properties in terms of hardness, impact strength and tensile strength ${ }^{[5]}$. Razzaq. A M et.al (2017) has investigated the microstructural characterization of fly ash particulate reinforced AA6063 Aluminium alloy for aerospace applications. The weight percentage of Fly Ash is varied from 2\%, to 6\% and the material is fabricated by compo casting technique. The result shows that the density of the AA6063-FA Composite decreases with increase of FA particulate weight fraction. It is also seen that the composite with $6 \mathrm{wt} \%$ of FA reinforcement exhibits higher compression strength ${ }^{[6]}$. Alaa Mohammed Razzaq et.al (2017) fabricated an Aluminium based hybrid composite with fly ash and Aluminium alloy 6063 using stir casting technique. The percentage of Fly Ash is varied as $0 \%, 2 \%, 4 \%, 6 \%, 8 \%, 10 \%$, $12 \%$. The result shows that the bulk density of the composite material decreases with an increase in reinforced fly ash particles. The Charpy impact strength is higher is pure AA6063 compared with other percentage of fly ash content. Also, the brittleness of the material increases with increase in the fly ash content ${ }^{[7]}$. Shivananda Murthy K.V et.al (2017) investigated the mechanical and thermal properties of AA7075/TiO2/Fly ash hybrid composites obtained by hot forging. The fly ash content was fixed to $3 \mathrm{wt} \%$ while that of $\mathrm{TiO}_{2}$ was varied from 2.5 to $10 \mathrm{wt} \%$. It is evident from the results that the thermal conductivity decreased which is mainly due to the absence of efficient electron-phonon coupling due to scattering of the electrons and phonons at the interface ${ }^{[8]}$.

Venkatachalam G and Kumaravel A (2017) fabricated and characterized the A356-Basalt Ash-Fly Ash composites which was Processed by Stir Casting Method. The result shows that the tensile strength of the composite with the combination of $90 \% \mathrm{Al}$ $+5 \%$ basalt $+5 \%$ fly ash increased while the hardness of sample with $90 \% \mathrm{Al}+7 \%$ basalt fiber ash $+3 \%$ fly ash increased. It was also seen that the sample with $90 \% \mathrm{Al}+3 \%$ basalt $+7 \%$ fly ash had lower wear ${ }^{[9]}$. David Rathnaraj J and Sathish S (2017) investigated the LM6 Metal Matrix Composite with borosilicate glass reinforcement fabricated by stir casting. The weight percentage of Borosilicate glass powder is varied from $2.5 \%, 5 \%$, $7.5 \%$, and $10 \%$. The result shows that tensile strength and compression strength increased with $7.5 \%$ of reinforcement while the impact strength increases as the \% reinforcement increases. However, it is evident that the density decreased with increase in the $\%$ of borosilicate reinforcement ${ }^{[10]}$. Yuvaraj. G et.al (2017) investigated the mechanical properties of Aluminium Alloy AA2219 reinforced with graphite in which the weight percentage of graphite powder is varied to $1.5 \%, 3 \%, 4.5 \%$. The composite material is fabricated by stir casting technique and the result shows that the composite with minimum graphite content has the maximum hardness ${ }^{[11]}$. Kumaravel. D et.al (2017) fabricated an Aluminium based composite material using fly ash. The weight percentage of Fly ash was varied to $5 \%, 10 \%, 15 \%$. The result shows that Hardness, tensile strength and impact test improved and moderate corrosion resistance is seen when the fly ash content is about $15 \mathrm{wt} \%{ }^{[12]}$. Tulasiram. $\mathrm{N}$ et.al (2017) investigated the microstructure and mechanical properties of Fly ash/SiC Particles Reinforced AA 7075 hybrid composites. Composites with weight percentages are 5, 10 and $15 \mathrm{wt} \% \mathrm{SiC}$ and Fly ash particulates of $70 \mu \mathrm{m}$ were fabricated using stir casting. The result shows that the density of the material decreases and the micro analysis shows the absence of voids and discontinuities in the composites with good interfacial bonding between the $\mathrm{FA} / \mathrm{SiC}$ particles and matrix phase ${ }^{[13]}$. Aldrin Sugin. M. S et.al (2017) has fabricated and characterized Aluminium 7075 - Fly ash metal matrix composite with analytical verification on the application in aircraft wings. The weight percentage of Fly ash is varied to $5 \%, 10 \%, 15 \%$. The material is fabricated by stir casting technique. The result shows that the impact, tensile, hardness of the composite increases and the density decreases ${ }^{[14]}$.
It is explicit from the above literatures that the composite material with Al 6063/Fly ash/Borosilicate has not been tried and tested. The presence of fly ash which is readily available in plenty and ceramic component, Borosilicate, will improve the mechanical characteristics of the metal matrix composite to a great extent. The present work is an attempt to fabricate and test the mechanical characteristics of Aluminium based metal matrix composites by combining fly ash and ceramic material (Borosilicate) so as to arrive at a composite with better capabilities than the parent material.

\section{Methodology}

The steps to be followed in fabricating the composite and analyzing the characteristics is shown below in the flow chart given in Fig. 1.

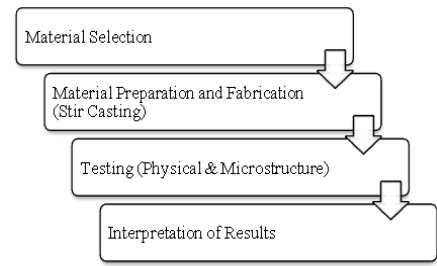

Fig. 1: Research methodology

\section{Material Selection}

The matrix material chosen for this study is AA6063 alloy. This Commercial grade Aluminium alloy 6063 was obtained from the local supplier. AA6063 has been chosen for the study because of its excellent characteristics like formability, higher corrosion resistance, better weldability, high strength-to-weight ratio, lower cost and the most economical. The Chemical composition of AA6063 is given below in Table 1 .

Table 1: Chemical Composition of AA6063 in Wt\%

\begin{tabular}{|c|c|}
\hline Elements in AA6063 & Wt\% \\
\hline $\mathrm{Cu}$ & $<0.01$ \\
\hline $\mathrm{Fe}$ & 0.19 \\
\hline $\mathrm{Mg}$ & 0.51 \\
\hline $\mathrm{Mn}$ & 0.04 \\
\hline $\mathrm{Si}$ & 0.86 \\
\hline $\mathrm{Ti}$ & 0.008 \\
\hline $\mathrm{Zn}$ & 0.01 \\
\hline $\mathrm{Cr}$ & 0.01 \\
\hline $\mathrm{Al}$ & Balance \\
\hline
\end{tabular}

Fly ash which is available in large quantities as a by-product from thermal power plants and a low cost material is chosen as reinforcement. Fly ash for this study is obtained from a brick kiln. Fly ash that helps in the overall weight reduction of the composite has the chemical composition as given in Table 2.

Another reinforcement used in the study is Borosilicate (Glass) which has optimum mechanical, thermal and chemical behavior. The Borosilicate is obtained from broken glass beakers from Chemistry laboratory. The chemical composition of borosilicate glass is given below in Table 3 .

Table 2: Chemical Composition of Fly Ash in Wt\%

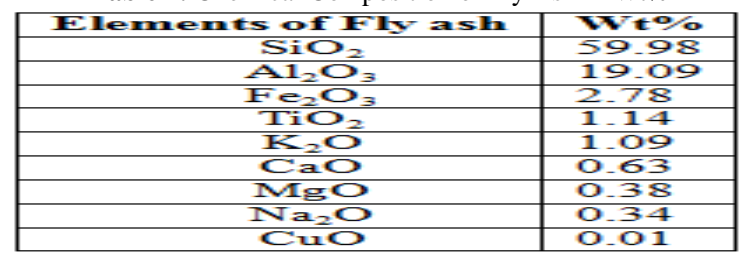

Table 3: Chemical Composition of Borosilicate in $\mathrm{Wt} \%$

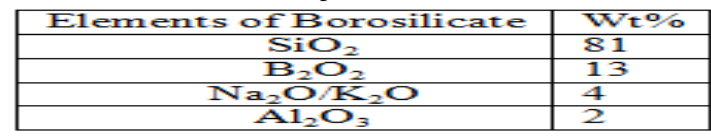




\section{Material Preparation and Fabrication Of Composite}

Stir casting method is used to prepare the metal matrix composite in this study. The stir casting apparatus used to fabricate the composite specimen is shown in Fig. 2.

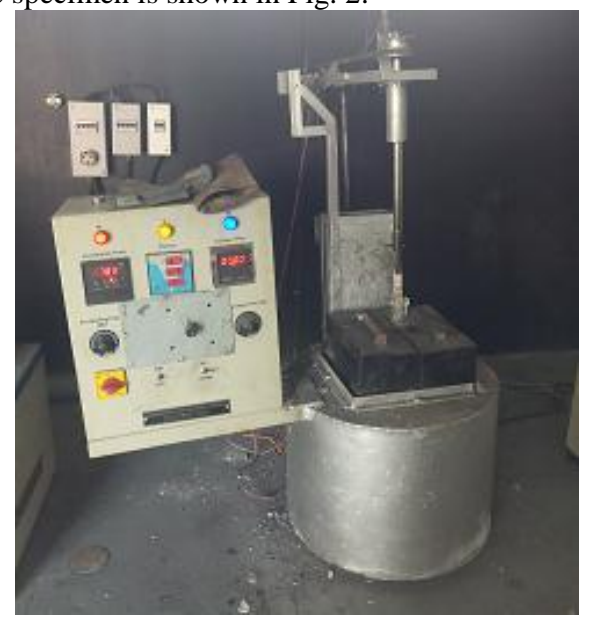

Fig. 2: Stir casting apparatus

Broken Borosilicate glass beakers from the laboratory is taken, cleaned and dried. Then the glass beakers are crushed in the Ball Mill Grinder and sieved to a size of 75 microns. Fly ash is dried under hot sun to make it free from moisture. Fly ash and the borosilicate glass powder are weighed for the respective volume percentage for each specimen and mixed together and placed in separate crucibles. These cubicles with the mixture are preheated to $400^{\circ} \mathrm{C}$. Similarly the Aluminium alloy is weighed and melted at $800^{\circ} \mathrm{C}$. Then the preheated reinforcement materials, fly ash and borosilicate glass powder are added constantly to the molten aluminium alloy and a small amount of magnesium is also added to the molten aluminium alloy to increase the wettability. The molten metal composite is stirred at $350 \mathrm{rpm}$ for $5 \mathrm{~min}$ after which it is poured into the die and allowed to solidify and cool. After 10 minutes of cooling the composite materials are removed from the die and cooled further cooled to room temperature. Similar method is followed to fabricate different specimens of composites at various proportions of reinforcements. The composition of the specimen used in this study is given in Table 4.

Table 4: Composition of The metal matrix composite used in the study

Table 4: Composition of The metal matrix composite used in the study
\begin{tabular}{|c|c|c|c|}
\hline Specimens & $\begin{array}{c}\text { AA6063 } \\
\text { (vol\%) }\end{array}$ & $\begin{array}{c}\text { Borosilicate } \\
\text { (vol\%) }\end{array}$ & $\begin{array}{c}\text { Fly ash } \\
\text { (vol\%) }\end{array}$ \\
\hline Specimen 1 (S1) & 100 & 0 & 0 \\
\hline Specimen 2 (S2) & 84 & 8 & 8 \\
\hline Specimen 3 (S3) & 84 & 4 & 12 \\
\hline Specimen 4 (S4) & 84 & 12 & 4 \\
\hline Specimen 5 (S5) & 84 & 2 & 14 \\
\hline Specimen 6 (S6) & 84 & 14 & 2 \\
\hline
\end{tabular}

A sample specimen obtained from stir casting is shown in Fig. 3.

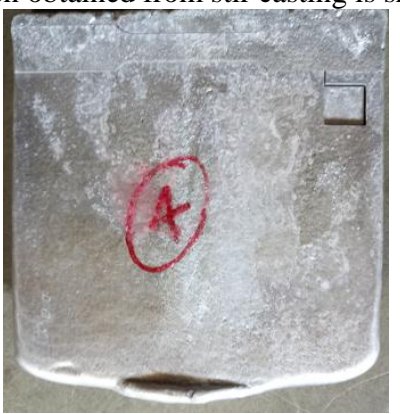

Fig. 3: Sample specimen of AA/FA/B used in the study

\section{Testing}

The specimen are subjected to various mechanical and micro structural analysis as stated below to find out the tensile, wear and

grain structure of the specimen. The analysis used in this study are:

\section{Tensile test}

The specimen was cut as per the ASTM standard E8M04 and computerized Universal Testing Machine is used to perform the tensile tests. The specimen as per the standard used to measure tensile strength is shown in Fig. 4.

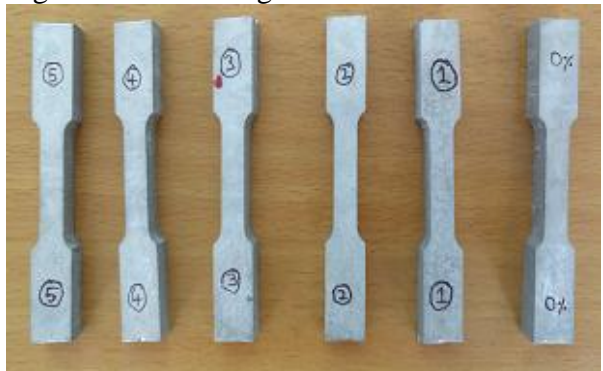

Fig. 4: Specimen of AA/FA/B as per ASTM E8M04 for Tensile test

\section{Hardness test}

Hardness of any material is the characteristic of the material which is the resistance offered by the material to indentation. The hardness of the specimen is measured using Vickers micro hardness apparatus in which the permanent depth of indentation using a indenter due to a fixed load is measured. The smaller the indentation, the material is said to be harder.

\section{Wear Test}

Wear test is conducted using a pin on disc wear testing machine. Pin-on-Disk wear testing is a method of characterizing the coefficient of friction, frictional force, and rate of wear between two materials. The Pin on disc wear tester used in the study is shown in Fig. 5.

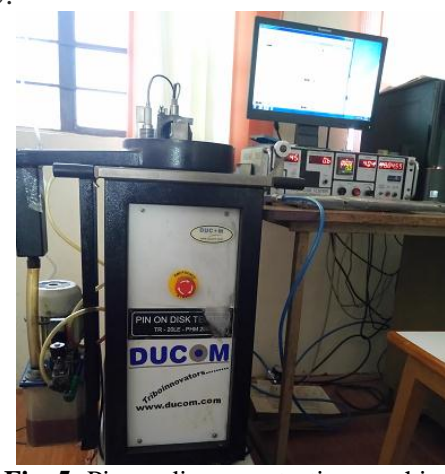

Fig. 5: Pin on disc wear testing machine

\section{Scanning Electron Microscopy}

Scanning Electron Microscopy (SEM) is a kind of electron Microscope that produces images of a sample by scanning it with a focused beam of electrons. SEM generates resolution images and precisely measures very small objects in the specimen. It can perform high magnification and gives high resolution images by raftering a focused electron beam across the surface and detecting secondary electron signal.

\section{Interpretation of Results}

The mechanical and microscopic analysis of the specimens are performed and the results are obtained as below :

\section{Tensile test}


The variation of tensile strength compared to 100\% AA6063 and other combinations of FA and B are shown in Fig. 6.

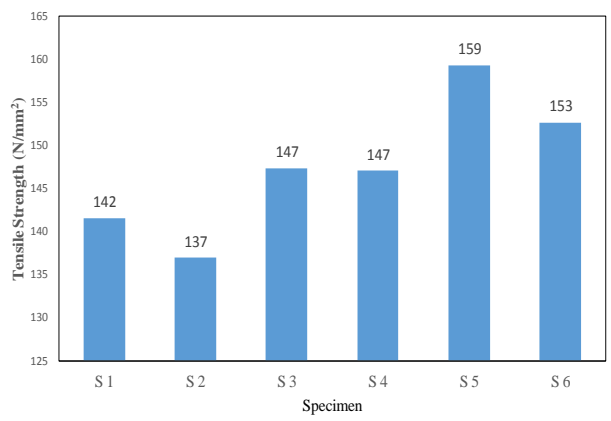

Fig. 6: Comparison of tensile strength in fabricated metal matrix composites

From Fig.6 it is evident that the specimen $5(84 \%$ AA, $2 \%$ B, $14 \% \mathrm{FA}$ ) shows greater tensile strength compared to the $100 \%$ AA as well as other combination of metal matrix composites. The presence of highest proportion of fly ash (14\%) in the specimen 5 is seen to exhibit maximum tensile strength of $159 \mathrm{~N} / \mathrm{mm}^{2}$. Hence, it is clear that the presence of fly ash has improved the tensile strength of the aluminium AA6063. The increase in tensile strength is about $11.97 \%$ for specimen 5 when compared to $100 \%$ AA. The next value of tensile strength $153 \mathrm{~N} / \mathrm{mm}^{2}$ is found in sample $6(14 \% \mathrm{~B}, 2 \% \mathrm{FA})$. It is seen that the tensile strength has increased $11.97 \%$ when the FA occupies $14 \%$ by volume and $7.75 \%$ increase when B occupies $14 \%$ of the composite by volume. Hence, it is evident that the presence of both FA and B contributes to the increase of Tensile strength of AA6063.

Fig. 7 shows the variation of $\%$ of elongation in aluminium alloy and the composites.

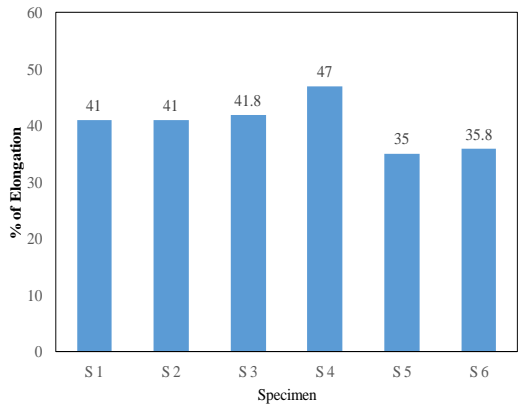

Fig. 7: Change in percentage of elongation of fabricated metal matrix composites

It is seen that the elongation attained by specimen 5 (84\% AA, $2 \%$ $\mathrm{B}, 14 \% \mathrm{FA})$ and specimen $6(84 \% \mathrm{AA}, 14 \% \mathrm{~B}, 2 \% \mathrm{FA})$ are found to be less than the other ones compared in this study. The same trend followed by the composites in tensile strength is seen here too. Hence, it may be concluded that the presence of more amoun of single reinforcement in the composite amounts to small reduction in ductility.

\section{Hardness}

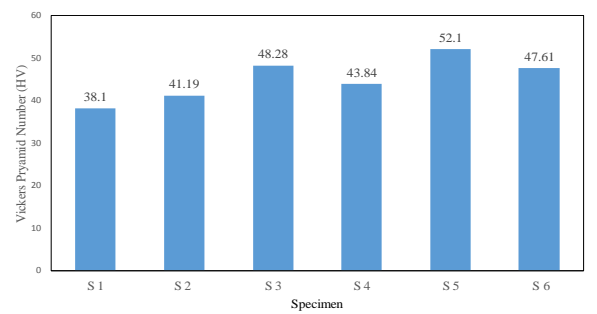

Fig. 8: Variation in percentage of elongation of fabricated metal matrix composites

Fig. 8 shows the variation of hardness in aluminium alloy and the composites. It is found that the hardness of specimen 5 (84\% AA,
$2 \% \mathrm{~B}, 14 \% \mathrm{FA}$ ) has the maximum hardness of $52.1 \mathrm{HV}$ followed by specimen $3(84 \% \mathrm{AA}, 4 \% \mathrm{~B}, 12 \% \mathrm{FA})$ with $48.28 \mathrm{HV}$. It is evident that, the presence of more amount of fly ash increases the hardness of the composite. The hardness of the composite increases by $36.75 \%$ and $26.72 \%$, when the fly ash content proportions are $14 \%$ and $12 \%$ respectively. Also, the hardness of specimen 6 ( $84 \% \mathrm{AA}, 14 \% \mathrm{~B}, 2 \% \mathrm{FA})$ is also increased by $24.9 \%$ when the FA content is less and B\% is maximum (14\%). Hence, it is once again found that the presence of reinforcements increases the hardness of the aluminium alloy to a great extent.

\section{Wear Test}

Wear test is carried out to predict the wear performance of the composites and to evaluate the wear property of the composite material so as to determine whether the material is adequate for specific wear applications. Every sample is tested in a pin disc wear testing machine with $2 \mathrm{kgf}$ load on a track of $80 \mathrm{~mm}$ diameter and a disc speed of $400 \mathrm{rpm}$ for a period of 30 minutes.

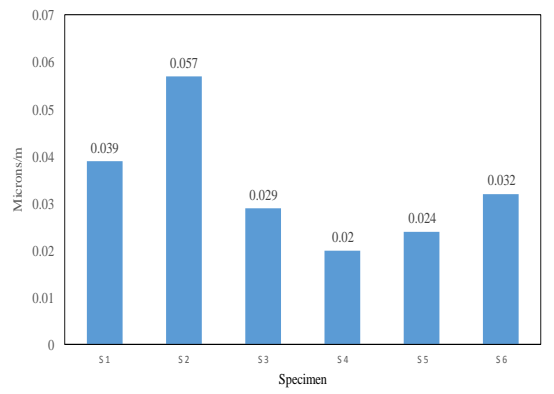

Fig. 9: Results of wear test on metal matrix composites

Fig. 9 shows the wear resistance of composite materials when compares to the wear resistance of pure $\mathrm{Al}$ alloy 6063. It is clearly seen that the specimen $4(84 \%$ AA, $12 \%$ B, $4 \%$ FA) registers the least wear and hence has the maximum wear resistance followed by specimen 5 ( $84 \%$ AA, $3 \%$ B, $14 \%$ FA). It is seen that the role played by both the reinforcements Borosilicate and Fly ash are almost same, as the wear is less when one of the reinforcement is at its maximum while the other is present in minimum. The wear is maximum when the reinforcements are found at equal proportions, say $8 \%$ in sample $2(84 \%$ AA, $8 \% \mathrm{~B}, 8 \% \mathrm{FA})$.

\section{Scanning Electron Microscopy}

The photographs of the micro structural analysis of the metal matrix composite $(\mathrm{AA} / \mathrm{FA} / \mathrm{B})$ are shown in Fig 11 \& 12 . Fig.10 shows the scanning electron micrograph of AA6063 alloy reinforced with $14 \%$ fly ash and $2 \%$ Borosilicate. The dark patches show the agglomeration and the bright spots show the presence of Borosilicate.

Fig.11 shows the scanning electron micrograph of AA6063 alloy reinforced with $8 \%$ fly ash and $8 \%$ Borosilicate in which the tensile strength is less among the analyzed specimens. It is seen that the ductile dimples are clearly defined in this specimen.

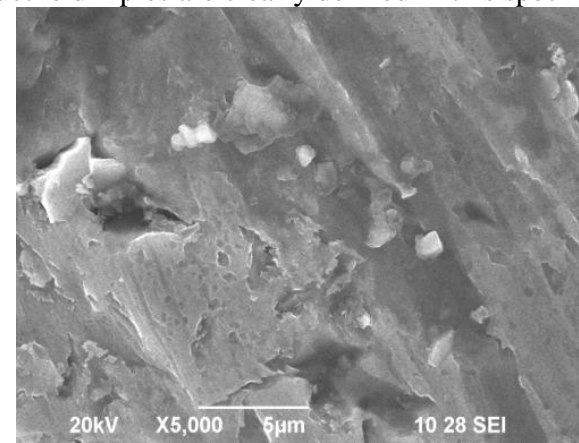

Fig. 10: SEM image of specimen 5 with $2 \%$ B and $14 \%$ FA 


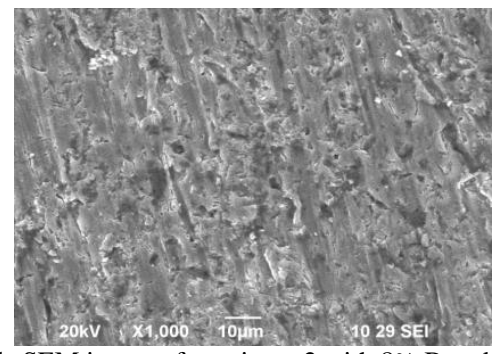

Fig. 11: SEM image of specimen 2 with $8 \% \mathrm{~B}$ and $8 \% \mathrm{FA}$

Energy Dispersive X-Ray Analysis (EDX), referred to as EDS or EDAX, is an $\mathrm{x}$-ray technique used to identify the elemental composition of materials. EDX systems provide the imaging capability of the specimen of interest. The data generated by EDX analysis consist of spectra showing peaks corresponding to the elements making up the true composition of the sample being analyzed.

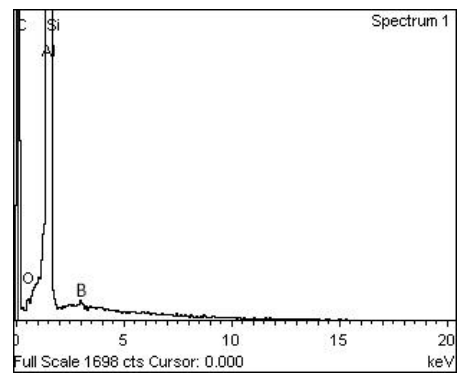

Fig. 12: EDX image of specimen 5 with $2 \%$ B and $14 \%$ FA

Fig. 12 shows the EDX image of the metal matrix composite of specimen 5 showing the presence of both the reinforcements.

\section{Conclusions}

Metal matrix composites of AA6063 with fly ash and Borosilicate as reinforcements were successfully developed using stir casting and the mechanical and micro structural analysis of the specimen were carried out. Six samples of AA6063 with various vol.\% of reinforcements were developed and analyzed. The following conclusions were obtained based on the study.

1. The presence of $14 \%$ vol. fly ash increases the tensile strength of the aluminium AA6063 by about $11.97 \%$ and at the same time, the presence of $14 \%$ vol. Borosilicate increases the tensile strength by $7.75 \%$. Hence, can be concluded that the presence of both FA and B contributes to the increase of Tensile strength of AA6063.

2. Similarly, the ductility of the composite reduces by $14 \%$ and $17 \%$ when one of the reinforcement is found in maximum vol. $\%$ in the composite.

3. The hardness of the composite increases by $36.75 \%$ and $26.72 \%$, when the fly ash content proportions are $14 \%$ and $12 \%$ respectively.

4. Similarly, the hardness of composite increases by $24.9 \%$ when the vol. \% of B is maximum (14\%). Thus, both the reinforcements increase the hardness of the aluminium alloy.

5. The wear is more when both the reinforcements are found in equal vol.\% in the composite. However, the wear is found to be minimum in the composite where the vol.\% of one reinforcement is at its maximum and the other is in its minimum.

6. The SEM and EDX images shows the dark patches of fly ash in the composite which indicates the increase in porosity as the vol.\% of fly ash in the composite increases.

Thus the AA6063 composite with 2\% Borosilicate and 14\% fly ash is found to have more desirable properties that make it suitable for high tensile and high wear applications in automobile and aerospace industries.

\section{Acknowledgment}

The authors would like to express their heartfelt thanks to $\mathrm{Mr}$. Devamanoharan and Mr. John Kennedy Mechanical Engineering, Mr. Gnanaprakasam, Civil Engineering and Mr. Raja, Nanotechnology for helping us in carrying out fabrication, Mechanical and microstructure analysis in their laboratories.

\section{References}

[1] Deepak S \& Mediratta SR, "Evaluation of the Mechanical Properties of Al 7075-Fly ash composite material”, International Journal of Innovative Research in Science, Vol.2, No.4, (2013)

[2] Sachin M, Ram N \& Gupta RD, "Synthesis and Characterization of Aluminium 6061 Alloy-Fly ash \& Zirconia Metal Matrix Composite", International Journal of Current Engineering and Technology, Vol.3, No.5, (2013).

[3] Vamsi Krishna M \& Anthony MX, "An Investigation on the Mechanical Properties of Hybrid Metal Matrix Composites ", 12th Global Congress on Manufacturing and Management, Procedia Engineering, Vol.97, (2014).

[4] Jamaluddin Hindi U, Achutha Kini SS, Sharma B, Gurumurthy M \& Gowri Shankar MC, "Mechanical Characterization of Stir Cas Al 6063 Matrix SiC Reinforced Metal Matrix Composites", 5th International Conference on Automotive, Mechanical and Materials Engineering, (2015).

[5] Rajesh PV \& Roseline S, "Experimental Investigation of Mechanical Properties of Aluminium alloy AL6063 based hybrid metal matrix composite", International Journal of Advances in Engineering Research, Vol.11, No.1, (2016).

[6] Razzaq AM, Abang Abdul Majid DL, Ishak MR \& Uday MB, "Micro structural characterization of fly ash particulate reinforced AA6063 Aluminium alloy for aerospace applications", AEROS Conference, IOP Conf. Series: Materials Science and Engineering, Vol.270, (2017).

[7] Alaa Mohammed R, Dayang Laila M, Mohamad RI and Uday MB, "Effect of Fly Ash Addition on the Physical and Mechanica Properties of AA6063 Alloy Reinforcement", Metals, MDPI, Vol.477, (2017).

[8] Shivananda Murthya KV, Girisha DP, Keshavamurthy R, Temel V \& Praveennath GK, "Mechanical and thermal properties of AA7075/TiO2/Fly ash hybrid composites obtained by hot forging", International Progress in Natural Science: Materials, Vol.27, (2017).

[9] Venkatachalam G \& Kumaravel A, "Fabrication and characterization of A356-Basalt Ash-Fly Ash Composites Processed by Stir Casting Method", Polymers \& Polymer Composites, Vol.25, No.3, (2017).

[10] David Rathnaraj J and Sathish S, "Investigations on LM6 Metal Matrix Composite with borosilicate Glass Reinforcement for Aerospace applications", ICRAAE, Materials Science and Engineering, Vol.247, (2017),

[11] Yuvaraj G, Bhuvaneswari V, Vignesh G \& Vairamuthu L, "Mechanical Properties of Aluminium alloy AA2219 Reinforced with graphite", First International Conference on recent Advances in Aerospace Engineering, Materials Science and Engineering, Vol.247, (2017).

[12] Kumaravel D \& Mohan Raj B, "Investigation of Aluminium Based Composite Material Using Fly Ash”, International Journal of Engineering Research in Mechanical and Civil Engineering, Vol.2, No.11, (2017).

[13] Tulasiram N \& manikanta K, "Microstructure and Mechanical properties of Fly ash/Sic Particles Reinforced AA 7075 Hybrid Composites", IOSR Journal of Mechanical and Civil Engineering, (2017).

[14] Aldrin Sugin MS, Subhash P \& S. Ramanuj, "Fabrication and Characterization of Aluminium 7075 - Fly ash Metal Matrix Composite with Analytical Verification on Application to Aircraft Wings", International Journal of Innovative Studies in Sciences and Engineering Technology, Vol.3, No.5, (2017).

[15] Venkatachalam G \& Kumaravel A, "Mechanical Behavior of Aluminium Alloy reinforced with Sic/Fly Ash/Basalt composite for Brake rotor", Polymers \& Polymer Composites, Vol.25, No.3, (2017). 